\title{
Modelling Mixed Farming Enterprises using AusFarm
}

\author{
Herrmann, N., Mayberry, D., Hochman, Z. and MacLeod, N. \\ CSIRO Agriculture \\ Email: neville.herrmann@csiro.au
}

\begin{abstract}
Australian agriculture faces challenges to improve the efficiency and profitability in the face of changing weather, regulatory and economic conditions. As farmers adapt to changing conditions and attempt to reduce risk, it is necessary to assess the mix and composition of their farm enterprises (e.g. cropping and livestock). Whole farm models are a useful tool that can be used in this decision making process.

The AusFarm software package has been designed to model biophysical systems and allow modelling of mixed crop and livestock farming systems. Cropping rotations, pasture mix, variability of soil types and integration of stock into these systems can be modelled successfully with AusFarm. Once a base simulation model has been constructed and tested, it is possible to modify management activities, cropping and stock parameters to examine how the production and natural resource management indicators are affected.
\end{abstract}

AusFarm has been used in a recent national, Commonwealth funded project to assess risks associated with strategic changes to farming enterprises in the southern wheat-sheep zone (Western Australia, South Australia, Victoria). A feature of this project has been the development of a decision support tool called Farm4Prophet. It is designed to examine questions such as; what would be the effect of decreasing the area used for cropping, or increasing the area sown to pasture, and increasing the size of the sheep flock? During development of this system several different mixed farming systems were modelled, and a range of scenarios were tested. To model these systems it was necessary to describe crop rotations, animal flock structures and management activities using AusFarm Management scripts. On-farm data were used to validate the baseline simulation designs.

This paper will describe the methodology used to model these farming systems and present the results.

Keywords: $\quad$ Mixed farming, AusFarm, simulation, decision support, Farm4Prophet 


\section{INTRODUCTION}

Farmers are pressured by a variety of factors such as markets, seasonal variations, regulations and available resources. As farmers adapt to changing conditions and attempt to reduce risk, they frequently assess the mix and composition of their farm enterprises (e.g. cropping and livestock). Whole farm models are a useful tool that can be used to help improve farming efficiency and profitability. The AusFarm modelling tool has been designed to give modellers the flexibility to build complex mixed farming systems that can be tested and examined with the intention of assessing various management options and enterprise mixes.

Farm4Prophet is a decision support tool being developed for mixed farming systems in the wheat-sheep zone of southern Australia. The tool is being delivered as a web based application similar to YieldProphet (Hochman et al., 2009). The Farm4Prohphet tool will allow users to assess risks associated with strategic changes to farming enterprises. For example, what would be the effect of decreasing the area used for cropping, or increasing the area sown to pasture, and increasing the size of the sheep flock? Farm4Prophet uses AusFarm to model the biophysical system and farm management activities.

The choice of AusFarm for this role has been based largely on its ability to incorporate and integrate the GrazPlan animal model (Freer et al., 1997) and the APSIM cropping models (Holzworth et al., 2014). There is a well documented history of modelling single enterprise systems but the number of tools and experience with building mixed enterprise simulations is much less. AusFarm has been used successfully to model various mixed farms (Moore et al., 2009).

As part of the development of the Farm4Prophet tool, AusFarm has been used to simulate a number of mixed farming systems as case studies. The case study farms included two cropping-only enterprises located in South Australia and Western Australia, and two mixed crop-livestock enterprises located in Victoria and South Australia. The cropping component of the farming systems are based on sowing crops on a rotational basis within distinct soil types. Modelling the animal component of the mixed farming systems required extensive use of the scripting facility that AusFarm supports (Moore et al., 2014) through a Manager component. Interactions between the cropping and animal enterprises include grazing the animals on crop stubble and dual purpose crops.

Some of the challenging aspects of building mixed farm models include tracking the cohorts of animals from year to year, handling reproduction, breeding animal replacements, building rules for grazing rotations, and supplemental feeding. Grazing rotations are one of the more complex procedures to build in a mixed farm simulation since there are many ways that a grower can choose to move animals around. Supplementary feeding can also become complex, particularly if different groups of animals are fed according to different criteria. In order to illustrate the versatility and power of the AusFarm framework for the Farm4Prophet application this paper reports methods used to represent one of the case study farms. In doing so a number of different characteristics of simulating mixed farming systems are addressed.

\section{CASE STUDIES}

The case study farms that were modelled as part of the Farm4Prophet project included cropping-only and mixed crop-livestock enterprises. The example below demonstrates how AusFarm is able to model a mixed farming system in South Australia.

Mixed Farm - Warooka, York Peninsula:

- Total farm size: $2186 \mathrm{ha}$ comprising three soil types

- Rotations: (1) Beans, wheat, barley, wheat, pasture (2) Pasture, wheat, barley, pasture, wheat, barley, pasture, beans (3) Pasture, wheat, pasture, barley

- Crops sown from late April. Pasture sown early April.

- Crop fertiliser applications at sowing and later top dressed

- Stubbles grazed

- Self-replacing Dohne Merino (DMo) flock, trading lamb flock, feed supplements used

The sheep enterprise consists of a self replacing wool flock and a trading lamb flock. Figure 1 describes the structure and the flows between age groups and classes of animals. The wool flock and trading lambs are grazed on pasture, crop and stubbles. When feed is limited they can be placed in the feedlot and fed supplement. Lambing is in May and weaning takes place in September. Breeding flock replacements are sourced from the young females and the number of replacements required to sustain the stocking rate are 
brought into the breeding flock. Surplus lambs are sold at a target weight in a specified period. Cast for age ewes are sold at 5.5 years old.

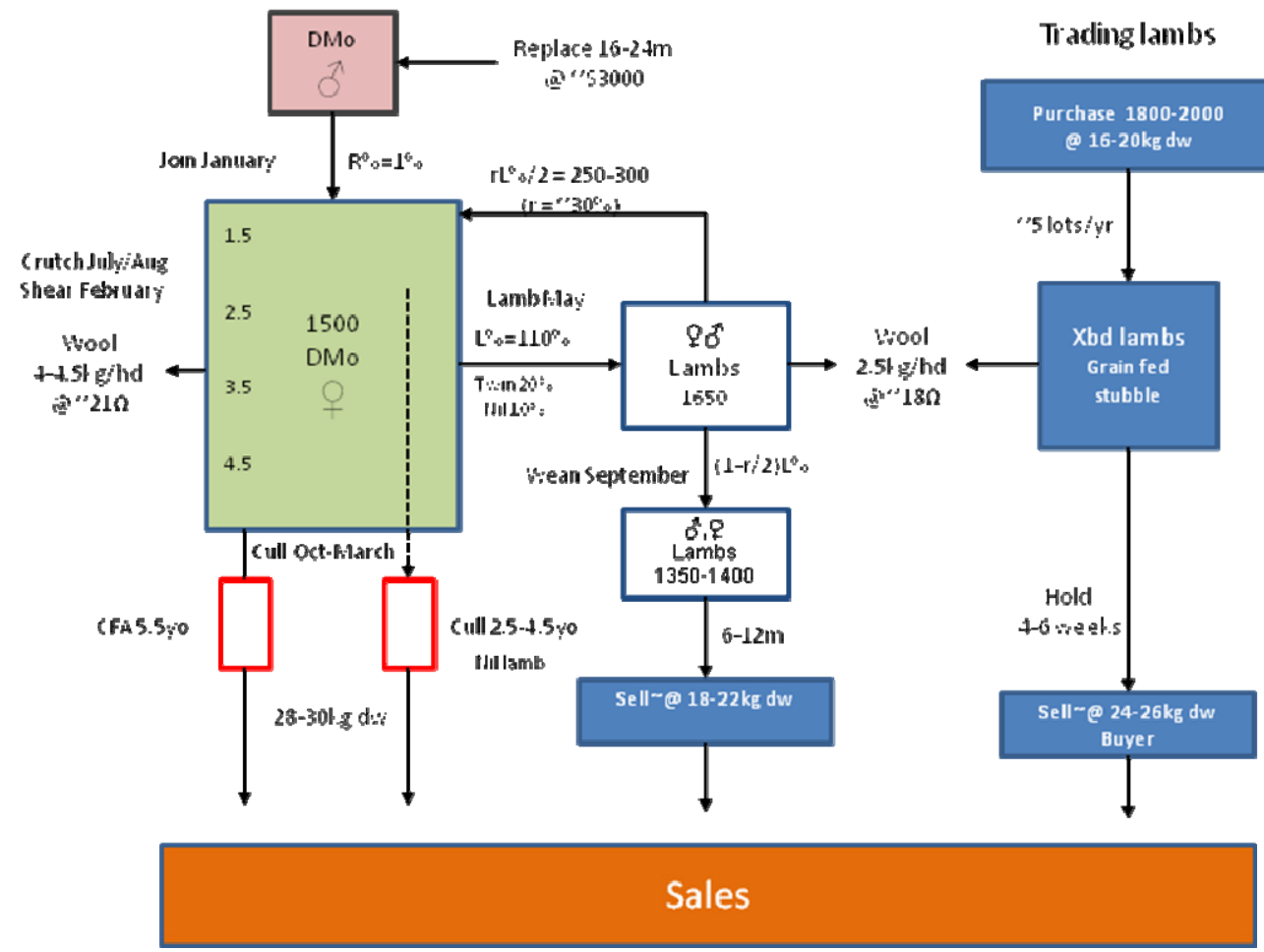

Figure 1. The flock structure showing the breeding flock and the trading lambs.

DMo: dohne merino, Xbd: crossbred, CFA: cast for age, dw: dressed weight

The mixed farming simulation shown in figure 2 contains the representation of the case study farming system. The model structure is shown in the left panel and some of the Management script in the right panel.

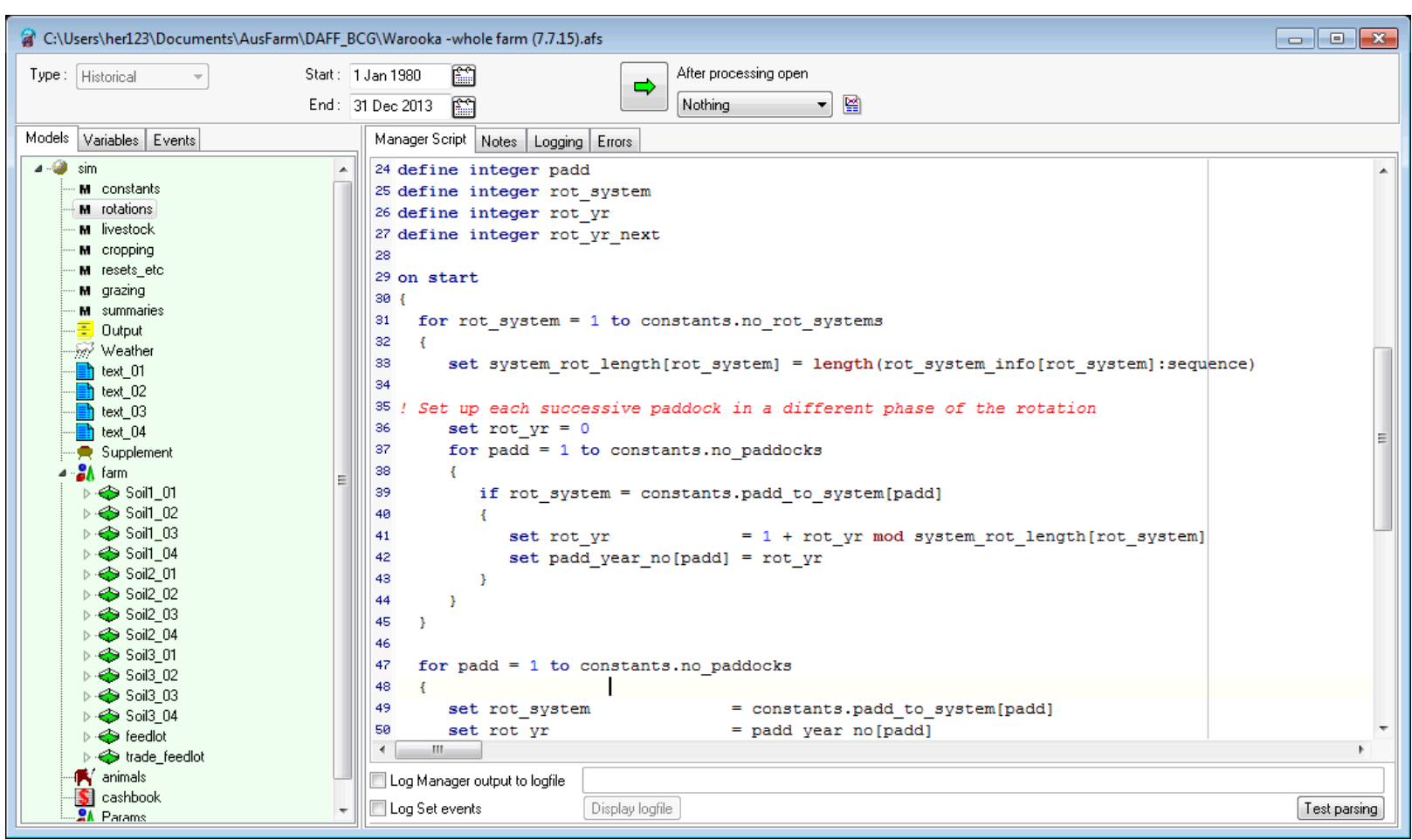

Figure 2. The representation of the mixed farm simulation in AusFarm. 
The tree of sub-model components on the left in figure 2 illustrates the hierarchical relationship and structure of some of the sub-models used in the simulation. A number of management scripts divide the management into areas such as the crop rotations, livestock management and grazing management. The paddocks in the simulation represent the soil type areas that are split into areas that support the various phases of the crop rotation. Each of these paddocks in-turn contains crops, pastures, soil water, soil nitrogen and surface organic matter sub-models as shown in figure 3. In AusFarm each of the APSIM sub-model components shown requires a 'translator' parent component that manages the differences in the way the components communicate within AusFarm.

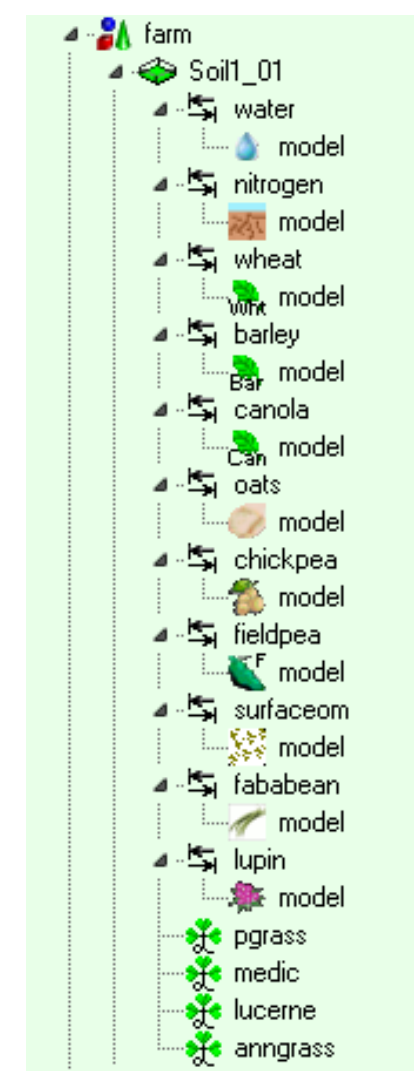

Figure 3. Example of the sub-model components used for a cropping paddock.

\section{DEVELOPING THE MODEL}

For managing livestock in AusFarm the animal sub-model maintains animals in groups of similar specification. These groups are able to be further grouped by assigning a tag number to them. Tags are important properties in AusFarm livestock scripts. By using tags it is possible to differentiate the activities to be carried out on selected animal groups. As animals progress between age classes or breeding groups their tags will be adjusted by the management script. The animals in the Warooka simulation are tagged in these groups:

- Merino replacement ewe

- Merino maiden dry ewe

- Merino maiden ewe

- Merino dry ewe

- Merino ewe

- Merino cull ewe

- Male lamb

- Female lamb

- Trade lamb

The management of livestock in this system is all contained in two Manager scripts; livestock and grazing. The key activities required in the livestock script are show below in table 1.

Table 1. Management activities in the Livestock management script.

\begin{tabular}{|l|l|}
\hline Activity & Steps required \\
\hline Initialising the flock structure & $\begin{array}{l}\text { Add all the age cohorts considering the stocking rate, mating date, weaning } \\
\text { date and enterprise type. Assign tags to the groups. Move the animals to } \\
\text { suitable grazing areas. }\end{array}$ \\
\hline
\end{tabular}




\begin{tabular}{|l|l|}
\hline Reproduction & $\begin{array}{l}\text { Find all the animals that are in tag groups which are suitable for mating and } \\
\text { mate them to the specified male. Reassign these animals to a new tag group } \\
\text { (e.g. merino dry ewes are tagged merino ewes). }\end{array}$ \\
\hline Weaning young & $\begin{array}{l}\text { Wean the young, tagging them male lamb and female lamb. Retag the } \\
\text { mothers as dry ewes. Split the weaned ewes for replacements required (tag } \\
\text { them merino replacement ewe). }\end{array}$ \\
\hline Shearing & Shear animals on specified dates. Store production information. \\
\hline Purchasing trade lambs & Buy the new animals. Tag them and place them in the feedlot. \\
\hline Sale of cull stock & $\begin{array}{l}\text { Sell any animals tagged as cull stock. Sell the oldest ewes reducing total } \\
\text { numbers to a level to maintain stocking rate. }\end{array}$ \\
\hline $\begin{array}{l}\text { Sale of young stock and trade } \\
\text { lambs }\end{array}$ & $\begin{array}{l}\text { Sell if at the target weight in the sale period or sell on the final date of the } \\
\text { sale period. }\end{array}$ \\
\hline Supplemental feeding & $\begin{array}{l}\text { Replenish the supplement store if required. Determine the condition score } \\
\text { feeding threshold required for the time of year. } \\
\text { For each animal type; determine if it requires supplement. Apply the } \\
\text { feeding rule required for this type of animal. If the animal is in the feedlot } \\
\text { then apply a different feeding rate. }\end{array}$ \\
\hline Monthly recording & $\begin{array}{l}\text { Store the opening and closing numbers and weights for animal groups. Store } \\
\text { the monthly totals for inputs and production. }\end{array}$ \\
\hline
\end{tabular}

Grazing is divided into different regimes: stubble grazing, pasture grazing, feedlot, and crop grazing. These phases are determined by the availability of the feed source, length of use and time of year. The grazing management script contains procedures shown in table 2 .

Table 2. Grazing activities in the Grazing management script.

\begin{tabular}{|l|l|}
\hline Activity & Steps required \\
\hline $\begin{array}{l}\text { Determine grazing period } \\
\text { type }\end{array}$ & $\begin{array}{l}\text { Calculate the type of grazing phase based on; time of year, suitable crop } \\
\text { growing, availability of pasture, time spent on stubble. } \\
\text { Grazing of the crop in a given paddock starts when a green mass threshold } \\
\text { is exceeded and crop phenology is appropriate. Grazing of each crop ends } \\
\text { when one or more of the following holds: green mass falls below a second } \\
\text { threshold, crop phenology reaches its threshold or total DSE-days (Dry } \\
\text { Sheep Equivalent consumption) in the paddock reaches a threshold. }\end{array}$ \\
\hline $\begin{array}{l}\text { Allocation of animals to } \\
\text { grazing location }\end{array}$ & $\begin{array}{l}\text { Determine the locations available for this grazing phase. Draft animals to } \\
\text { available locations. }\end{array}$ \\
\hline
\end{tabular}

Cropping management is controlled primarily through the cropping script as shown in table 3 . Another rotation script manages the sequence of cropping rotations.

Table 3. The cropping activities contained in the Cropping management script.

\begin{tabular}{|l|l|}
\hline Activity & Steps required \\
\hline Sowing crops & $\begin{array}{l}\text { Determine the accumulated rainfall and soil moistures. Choose the } \\
\text { paddocks to be sown based on rotation, area, and environmental values. } \\
\text { Kill the weeds and pastures (from a previous phase in the rotation) if } \\
\text { required. }\end{array}$ \\
\hline Harvesting & $\begin{array}{l}\text { Harvest any ripe crop and calculate the spilt grain amounts. Spilt grain will } \\
\text { be available to livestock grazing crop stubbles. }\end{array}$ \\
\hline Apply fertilizer & Calculate the amount of fertiliser to apply to each paddock based on the \\
\hline
\end{tabular}




\begin{tabular}{|l|l|}
\hline & $\begin{array}{l}\text { crop sown, growing season rainfall, soil } \mathrm{N} \text { and the crop rule to apply. } \\
\text { Apply fertiliser. }\end{array}$ \\
\hline Sowing pasture & $\begin{array}{l}\text { When pasture is to be sown in any paddock; sow it if there has been } \\
\text { sufficient rainfall and there is insufficient root mass existing. }\end{array}$ \\
\hline Spraying pasture & Spray when the weed mass level is exceeded or on the specified day. \\
\hline
\end{tabular}

The implementation of the rules in the AusFarm Manager relies on the ability of the script to query properties of any sub-model and trigger events in them. The Manager script language incorporates a facility to address sub-model components in the simulation by reference. In the code fragment in figure 4, the name of the crop model has been stored as a text string and used to specify which crop sub-model to address. The '@, indirection operator is used to address the entity referred to by the concatenated text string.

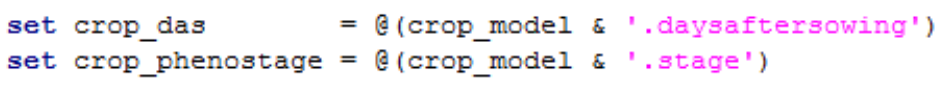

Figure 4. Accessing sub-model properties using indirection.

This technique is extremely useful for writing efficient and compact management scripts where multiple paddocks, animal groups, crops and pastures are used.

In a mixed farming system iterating over these entities is a frequent operation and is shown in the code fragment in figure 5.

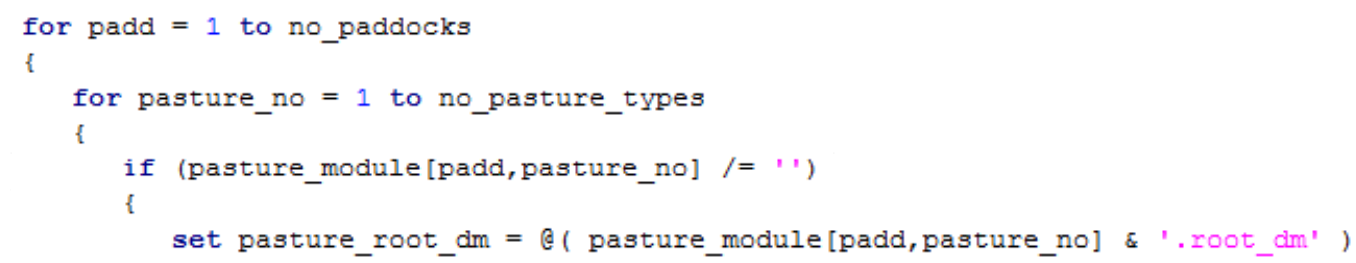

Figure 5. Iterating over paddocks and pastures and using indirection to reference the sub-models.

\section{ACCESSING THE RESULTS}

The simulation results for the mixed farm simulation are stored in three text format files. The results give a summarised picture of production and flow of animals in the simulation. The output files are listed in table 4.

Table 4. The output files generated by the simulation.

\begin{tabular}{|l|l|}
\hline Yearly summary & $\begin{array}{l}\text { Total areas sown to each crop type, crop type yields, N applied to crop type, yield for } \\
\text { crop type in each soil type. }\end{array}$ \\
\hline $\begin{array}{l}\text { Monthly crop } \\
\text { summary }\end{array}$ & Crop type yield, N applied to crop type. \\
\hline $\begin{array}{l}\text { Monthly livestock } \\
\text { summary }\end{array}$ & $\begin{array}{l}\text { For each animal class: opening and closing animal numbers for the month, opening } \\
\text { weights, opening ages, numbers shorn, wool harvested, sale numbers, sale weights, } \\
\text { numbers purchased, purchase weights, amount of supplement fed. }\end{array}$ \\
\hline
\end{tabular}

\section{INTEGRATION INTO FARM4PROPHET}

The Farm4Prophet system uses a web client interface. The data entry on this interface includes soil types, geographic location, livestock description and cropping rotations. The initial values are then available to configure the AusFarm simulation that will model the biophysical system. The integration of AusFarm into Farm4Prophet relies on a key feature of AusFarm where each simulation is fully described in a XML document. Farm4Prophet customises the XML template of an AusFarm simulation which is then processed by the simulation engine on a remote server. Production outputs are then used by a customised financial 
package (Hutchings \& Nordblom, 2011) to give summaries of the user's scenario enabling them to examine profit and risk for their farming system.

Being able to configure farming simulations from the Farm4Prophet decision support tool has required careful understanding of the driving factors or inputs that are required to examine mixed farm management questions.

\section{CONCLUSION}

Modelling a mixed farm in AusFarm requires a clear understanding of the rules that govern the purchase, sale, movement, and feeding of the animals in their livestock enterprise and also how to implement cropping rotations. The overlaps between the enterprises also need to be understood so that interactions are representative of real-life mixed farms. Writing management scripts to build a complete mixed farm can be challenging and may take a number of iterations of refinement. The ability to customise the farm management extensively using scripts can be expensive in terms of time and can take considerable effort but has many benefits. Once a general mixed farm has been constructed in AusFarm it can be a good template or starting point for representing many similar scenarios.

The Farm4Prophet decision support tool is a step forward in bringing complex mixed farm modelling into the hands of the 'non-modelling' community. The potential to broaden the range of supported management options through further development will mean that the system will be flexible and maintain its relevance for advisors and producers.

\section{REFERENCES}

Freer, M., Moore, A.D., Donnelly, J.R., (1997). GRAZPLAN: decision support systems for Australian grazing enterprises. II. The animal biology model for feed intake, production and reproduction and the GrazFeed DSS. Agric. Syst. 54 (1), 77-126.

Herrmann, N.I., Zurcher, E.J., (2011). Designing decision support systems for factorial analyses. In: Chan, F., Marinova, D., Anderssen, R.S. (Eds.), 19th International Congress on Modelling and Simulation: Perth, Australia, pp. 1209-1215.

Hochman, Z., van Rees, H., Carberry, P.S., Hunt, J.R., McCown, R.L., Gartmann, A., Holzworth, D., van Rees, S., Dalgliesh, N.P., Long, W., Peake, A.S., Poulton, P.L., McClelland, T., (2009). Re-inventing model-based decision support with Australian dryland farmers. 4. Yield Prophet ${ }^{\circledR}$ helps farmers monitor and manage crops in a variable climate. Crop Pasture Sci. 60 (11), 1057-1070.

Holzworth DP, Huth NI, deVoil PG, Zurcher EJ, Herrmann NI, McLean G, Chenu K, van Oosterom EJ, Snow V, Murphy C, Moore AD, Brown H, Whish JPM, Verrall S, Fainges J, Bell LW, Peake AS, Poulton PL, Hochman Z, Thorburn PJ, Gaydon DS, Dalgliesh NP, Rodriguez D, Cox H, Chapman S, Doherty A, Teixeira E, Sharp J, Cichota R, Vogeler I, Li FY, Wang E, Hammer GL, Robertson MJ, Dimes JP, Whitbread AM, Hunt J, van Rees H, McClelland T, Carberry PS, Hargreaves JNG, MacLeod N, McDonald C, Harsdorf J, Wedgwood S, Keating BA (2014) APSIM - Evolution towards a new generation of agricultural systems simulation. Environmental Modelling \& Software 62, 327-350. doi:10.1016/j.envsoft.2014.07.009.

Hutchings, T. \& Nordblom, T. (2011). A financial analysis of the effect of the mix of crop and sheep enterprises on the risk profile of dryland farms in south-eastern Australia. Australian Journal of Farm Business Management, 8: 19-41.

Moore AD, Bell LW, Revell DK (2009) Feed gaps in mixed-farming systems: insights from the Grain \& Graze program. Animal Production Science 49, 736-748. doi:10.1071/AN09010.

Moore, A.D., Holzworth, D.P., Herrmann, N.I., Brown, H.E., deVoil, P.G., Snow, V.O., Zurcher, E.J., Huth, N.I., (2014). Modelling the manager: Representing rule-based management in farming systems simulation models, Environmental Modelling \& Software, 62, Dec 2014, 399-410, http://dx.doi.org/10.1016/j.envsoft.2014.09.001 